\section{European satellite reception}

\section{Paris}

THERE is now hope that the European Remote Sensing Satellite, ERS-1, to be launched next year, will have an enthusiastic band of users. That seems to be the outcome of last month's meeting between the director-general of the European Space Agency (ESA), Reimar Lüst, and the President of the Commission of the European Communities (EC), Jacques Delors.

The satellite will allow Europe to have a major role in studying the world climate and the effects of pollution. But although the infrastructure of ground stations to receive data from ERS-1 is already in place, the network of potential users is still relatively underdeveloped but last month's meeting seems to have helped.

ERS-1 will also be at the heart of the World Ocean Circulation Experiment (WOCE), which will come alive, after 10 years of preparation, with the satellite's launch. Its advanced radar instrumentation will allow accurate data to be collected on sea surface temperatures, ice flows and ocean circulation, as part of an international effort to understand global

climate and natural disasters. The satellite could also be used to monitor the rate of destruction of tropical rain forests, often invisible to other remote-sensing satellites because of cloud cover.

The meeting between Delors and Lüst was aimed at soldering links between ESA and the European Community. "The European Commission is like a dream client", said Jean Arets, head of international relations at ESA. One possibility seems to be a high-level working group to encourage environmental monitoring by satellite. Arets also says that the European Community could help to finance the creation of a community of users.

The goals of ESA and the EC are reciprocal. ESA is keen to improve its coordination with the EC's new technology programmes, while the $\mathrm{EC}$ wishes to strengthen pan-European involvement in ESA programmes for Earth observation. It also seeks a long-term strategy to exploit microgravity techniques, and has an even more immediate need of common norms for telecommunications.

Peter Coles

\section{AURORALSATELLITE}

\section{Japan continues in an old furrow}

\section{Tokyo}

THE first satellite designed specifically for study of the particle acceleration mechanisms producing the aurora borealis (and australis) was launched successfully last week (22 February) by Japan's Institute of Space and Astronautical Science (ISAS) from the Kagoshima Space Center.

The EXOS-D satellite was carried into a polar orbit by a Mn-3S II three-stage solid-tuel rocket, independently developed under ISAS's scientific space research programme. The 300-kg satellite, given the post-launch name of 'Akebono' (Dawn), will fly into the region where charged particles from the solar wind are accelerated by the Earth's magnetic field and penetrate to the upper atmosphere, causing auroral displays. The orbit will take the satellite from a near point of $300 \mathrm{~km}$ from Earth out to $10,000 \mathrm{~km}$.

On board Akebono are instruments to monitor magnetic and electric fields, plasma waves, low-energy particles, supra-thermal ions and thermal electrons as well as a special auroral camera designed to take photographs in the visual and ultraviolet spectrum. Early next year, ISAS hopes to add to Akebono's view by launching sounding rockets capable of reaching a height of 350 kilometres from a base in Norway, making it possible to obtain the first simultaneous observations of the aurora from above and below.

Akebono is ISAS's 12th scientific observation satellite and the third in a

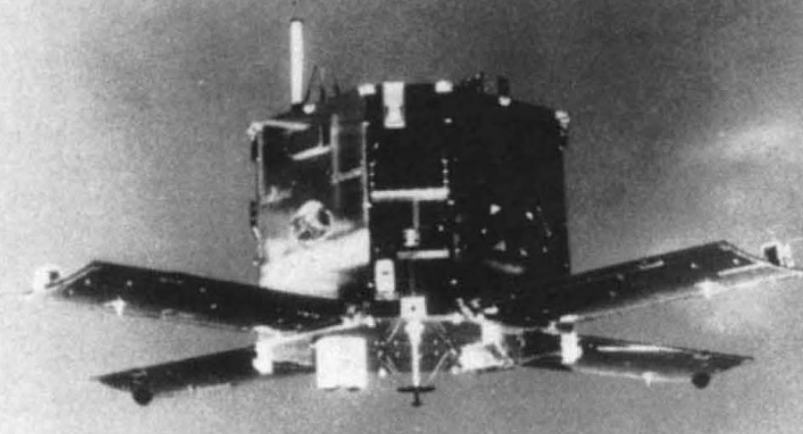
Akebono: a first in aurora research.

magnetosphere, following on from Kyokko ('Northern lights') and Jikiken ('Magnetosphere'). ISAS plans to continue providing a key role for Japanese researchers in solar wind and magnetospheric research with the launch of a satellite into the Earth's magnetotail in 1992 as a part of the International Solar Terrestrial Physics programme. Alun Anderson series designed to look at the aurora and

\section{Close call in election fight}

\section{Tokyo}

A rough election battle for the presidency of the University of Tokyo resulted in victory last week for Professor Akito Arima, one of the chief proponents of major change for Japan's leading university.

The election was so close that the university was eventually compelled to choose between two candidates by asking them to draw straws (actually a pair of bamboo sticks with concealed, differently coloured tips). It is the first time that this chance procedure has had to be used in the 112-year history of the university.

Arima (58), a theoretical nuclear physicist, will become president of the university for a four-year term beginning on 1 April. He is the first president to come from the science faculty for more than thirty years and faces a university which is divided over the plans for radical educational reform led by the science faculty.

The science faculty's plans involve fusing undergraduate and graduate schools into a new six-year school (see Nature 330, 597; 17 December 1987). But opponents fear it may lead to a drop in prestige for the College of General Education, whose faculty provides the first two years of education to all students and less-specialized further education in departments of Liberal Arts and Pure and Applied Sciences

Department of Liberal Arts' Professor Nagoya Homma, who has opposed the reform plan, proved to be Arima's chief opponent.

To begin with, there were five candidates and after three rounds of voting the two top candidates both drew exactly 586 votes from the assembled professors, associate professors and lecturers of the university.

At that point, previously unused university rules specified a decision by lottery and Arima drew the winning redtipped stick.

"Exhausting" was how one Senate member described the day-long election. But a much longer campaign lies ahead for those favouring reform. The members of the science faculty have seen top university research institutes turn into independent national facilities with excellent equipment and have seen private companies set up basic research institutes with large financial resources. Without some strengthening of the university research system, the science faculty are apprehensive that they will find themselves seen as a source of trained students rather than as leading basic researchers. 